\title{
The Effect of a Thinking Strategy Approach through Visual Representation on Achievement and Conceptual Understanding in Solving Mathematical Word Problems
}

\author{
Nasarudin Abdullah $^{1}$, Effandi Zakaria ${ }^{1} \&$ Lilia Halim ${ }^{1}$ \\ ${ }^{1}$ Department of Educational Methodology and Practice, Faculty of Education, Universiti Kebangsaan Malaysia, \\ Bangi, Selangor, Malaysia \\ Correspondence: Effandi Zakaria, Department of Educational Methodology and Practice, Faculty of Education, \\ Universiti Kebangsaan Malaysia, 43600 UKM Bangi, Selangor, Malaysia. Tel: 60-3-8921-6277; 60-19-223-3268. \\ E-mail: effandi@ukm.my
}

Received: September 20, 2012

Accepted: November 7, 2012 Online Published: November 30, 2012

doi:10.5539/ass.v8n16p30

URL: http://dx.doi.org/10.5539/ass.v8n16p30

\begin{abstract}
This quasi-experimental study was designed to determine the effect of a thinking strategy approach through visual representation on the achievement and conceptual understanding in solving mathematical word problems in primary school. The experimental group $(\mathrm{n}=96)$ was exposed to the treatment, while the control group ( $\mathrm{n}=$ 97) received a conventional approach in teaching and learning mathematical problem solving. To control the variable difference, a pretest was given to both groups before teaching. After 10 weeks of instruction, both groups were given a posttests. Two types of instruments were used to collect the data: the achievement and the conceptual understanding tests. To determine differences between groups, pre and posttests were analyzed using multivariate analysis of variance (MANOVA) followed by univariate analysis of variance (ANOVA). MANOVA results showed a significant difference in overall achievement and understanding of the concept of mathematical word problem solving for the treatment groups as compared to the control group. The ANOVA test of the findings also found that there were significant differences between treatment and control groups. Results showed that students who were exposed to the approach of thinking strategies through visualization representation in mathematical word problem solving outperformed students in conventional classes in achievement and conceptual understanding in mathematical word problem solving. Effect size is high, and therefore the treatment effect is meaningful in practice.
\end{abstract}

Keywords: strategic thinking approach, visualization, achievement test and conceptual understanding, mathematical word problems

\section{Introduction}

Problem solving is a major focus in the teaching and learning of mathematics and also one of the components that should be emphasized in school mathematics (Ministry of Education, 2000, 2002). Principles and Standards for School Mathematics suggested that students should master problem-solving skills, particularly mathematical word problems (National Council for Teachers of Mathematics [NCTM], 2000). In order to master mathematical word problem solving, they need the support of thinking strategies that will govern the interpretation and manipulation of information through language skills and visual capabilities in working memory (Geary, 2004). This is because mathematical word problems include worded items and their structure makes them difficult to solve. The problems need to be analyzed and interpreted as the basis for selection and decision making (Johnson, 2010; Lager, 2006). To achieve this goal, students need to be guided and exposed to strategic thinking and representation skills so that mathematical problem-solving skills can be achieved effectively (Kilpatrick \& Swafford, 2002; Montaque, 2003; Hanich \& Jordan, 2004; Powell et al., 2009). It is necessary to build a relationship between knowledge of language and knowledge to manipulate, in addition to the development of thinking processes and representation skills in building a relationship between all the important parts in a problem. Many studies show that success in mathematical word problem solving is supported by visual reasoning to inspire ideas and allow a deeper understanding of a relationship (Stylianou, 2002; Knight, 2000: Parkinson \& Redmond, 2002; Mohd Daud, 2002). 


\subsection{Purpose of the Study}

This study aims to develop a mathematical word problem-solving approach based on a thinking strategy through visual representation. The study will also look at the effectiveness of its implementation on student achievement and conceptual understanding.

\subsection{Objectives of the Study}

In particular, the objectives of this study are to:

1) Determine the differences in students' achievement in test performance between control and experimental groups.

2) Determine the differences in conceptual understanding between control and experimental groups.

\subsection{Research Hypothesis}

Null hypothesis:

Ho $_{1}$ : There is no significant difference in students' achievement in test performance between the experimental group and the control group.

$\mathrm{Ho}_{2}$ : There is no significant difference in students' conceptual understanding between the control group and experimental group.

\section{Materials and Methods}

The research was conducted using quasi-experimental design (Nonequivalent Control Group Design). The sample consists of 193 students in five primary schools in Pahang. Students in the experimental group received treatment of the thinking strategy approach through visual representation in mathematical word problem solving. The treatment lasted for four hours each week for ten weeks. Students in the experimental group were given a set of printed materials used in teaching and learning activities. Participants in the control group attend classes as normal class learning with the use of resources such as KBSR mathematics textbooks, through the conventional approach based on procedural understanding involving drills (memorizing facts or mathematical formulas). Two instruments were used in this study, the achievement test and the conceptual understanding instrument. The achievement test consists of 20 items. The concept of knowledge instrument was aimed at assessing the student knowledge of important mathematical concepts needed to solve mathematical word problems. Every mathematical word problem has been revised and is guided by a rubric adapted from the NWREL Mathematics Problem Solving Scoring Guide (2000) and Schommer-Aikins, Duell, and Hutter (2005).

\section{Results}

Table 1 shows the mean scores and standard deviations for the pretest and posttest according to experimental and control groups.

Table 1. Mean scores of pretest, posttest, and the standard deviation of the dependent variable

\begin{tabular}{lllll}
\hline Variables & \multicolumn{2}{l}{ Pretest } & Posttest \\
\cline { 2 - 4 } & Experiment & Control & Experiment & Control \\
\hline Achievement Test & 36.93 & 37.56 & 75.75 & 60.32 \\
Mean & $10: 32$ & 11.04 & $11: 45$ & 16.02 \\
Standard Deviation & & & & \\
Conceptual Understanding & $17: 35$ & 18.03 & 40.48 & 30.07 \\
Mean & 6.95 & 6.60 & 6.69 & $8: 58$ \\
Standard Deviation & & & & \\
\hline
\end{tabular}

3.1 Pre-test Analysis

Based on the one-way multivariate analysis of variance (MANOVA), as shown in Table 2, there is no significant difference between the experimental group and the control group. Univariate analysis showed similar results. There were no significant differences between groups for pretest achievement, $\mathrm{F}(1,191)=0: 17, \mathrm{p}=0.69, \mathrm{p}>$ $0.05, \eta^{2}=0.001$, and conceptual understanding, $\mathrm{F}(1,191)=0.48, \mathrm{p}=0.49, \mathrm{p}>0.05, \eta^{2}=0.003$. These results indicate no difference in score between the experimental group and the control group for the dependent variable of the pretest. At the initial stage of this study, all variables are equivalent, i.e. there is no difference between the experimental group and control group. 
Table 2. Results of multivariate analysis of variance (MANOVA) and analysis of variance (ANOVA) for the pretest

\begin{tabular}{llll}
\hline Variables & Multivariate $\mathrm{F}$ & Univariate $\mathrm{F}$ & Probability \\
\hline & $\mathrm{df}=2$ & $\mathrm{df}=(1,191)$ & $(\mathrm{P})$ \\
Group & 0.99 & & 0.42 \\
Achievement Test & & 0.17 & 0.69 \\
Conceptual Understanding & & 0.49 & 0.49 \\
\hline
\end{tabular}

3.2 Post-test Analysis

As shown in Table 3, there is a significant difference between the experimental group and the control group. Following that, it allows the next test to be conducted which is the univariate ANOVA test. The result of the univariate ANOVA test shows that there is a main effect of the approach towards the achievement test, $\mathrm{F}(1,191)=$ $59.18, \mathrm{p}<0.01, \eta^{2}=0.24$, and the conceptual understanding test, $\mathrm{F}(1,191)=88.17, \mathrm{p}<0.01, \eta^{2}=0.32$.

Table 3. Results of the MANOVA and ANOVA for post tests

\begin{tabular}{llll}
\hline Variable & Multivariate $F$ & Univariate $F$ & Probability \\
\hline & $\mathrm{df}=2$ & $\mathrm{df}=(1,191)$ & $(\mathrm{p})$ \\
Effect of the approach & 92.82 & & 0.00 \\
Achievement test & & 59.18 & 0.00 \\
Conceptual understanding test & & 88.17 & 0.00 \\
\hline
\end{tabular}

From the analysis, it can also be seen that the effect size of the two dependent variables is large, having $\eta^{2}$ value (eta squared) of 0.19 to 0.60 (Cohen, 1988, p.22). According to Kiess (1996), generally, $\eta^{2}$ value (eta squared) of 0.10 to 0.15 show strong treatment effects. In other words, the approach followed by the students shows a main effect of the students' capabilities. $\mathrm{R}^{2}$ value also shows that the approach contributes about 0.237 or $27.3 \%$ to the achievement score and 0.316 or $31.6 \%$ to the understanding of concepts.

\subsection{Strategic Thinking Approach Through Visual Representation in Solving Mathematical Word Problems}

In this research, the process in solving mathematical word problems is conducted through two main stages which are translations of problems based on language and computation process (Lesh \& Harel, 2003). According to Presmeg (1986) and Stylinou (2002), translation refers to translating the sentences into other representations either through a mental picture or visual image. The visual representation in this research refers to representation through a visual image of a rectangle figure; this representation is built by means of a few strategic information processing methods and applied under a specific sequence. The use of good representation enables students to interpret and comprehend information obtained through the strategic thinking steps listed below: 


\begin{tabular}{|c|c|c|}
\hline \multicolumn{2}{|c|}{ Steps } & Activities Implementation Guide \\
\hline $\begin{array}{l}\stackrel{90}{\stackrel{\Xi}{E}} \\
\frac{\vec{E}}{a}\end{array}$ & $\begin{array}{l}\text { 1. Understand the } \\
\text { Problem }\end{array}$ & $\begin{array}{l}\text { 1.1 Read and understand the problem } \\
\text { Read and understand the problem. Read repeatedly until the problem is } \\
\text { understood. } \\
\text { Underline important information/focus on the important points. } \\
\text { Identify what is given and what is required. } \\
\text { 1.2 Link the problem with previous knowledge } \\
\text { Have you encountered this problem before? } \\
\text { How to solve it? } \\
\text { 1.3 Picture the problem with your own words or build your own visual } \\
\text { representation. } \\
\text { Either in the form of figures/models to help solve complex problems }\end{array}$ \\
\hline \multicolumn{3}{|c|}{ * Self-reflection: Have I understood the problem and am I ready to proceed to the next step? } \\
\hline \multirow[b]{2}{*}{ 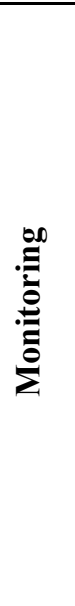 } & 2. Plan the Strategies & $\begin{array}{l}\text { 2.1 Plan and consider a few strategies that will be implemented } \\
\text { What are some of the suitable strategies? } \\
\text { 2.2 Translate the information given into visual representation figures } \\
\text { Draw and build figures/models. }\end{array}$ \\
\hline & $\begin{array}{l}\text { 3. Implement the } \\
\text { Strategies }\end{array}$ & $\begin{array}{l}\text { 3.1 Conduct calculations } \\
\text { Identify the operations involved. } \\
\text { Always remember the sequence of steps. } \\
\text { Determine the right time to proceed with the steps. } \\
\text { Choose the next steps. } \\
\text { Verify the strategies used to solve the problem. } \\
\text { Execute all processes involved. }\end{array}$ \\
\hline \multicolumn{3}{|c|}{ * Self-reflection: Have I known the methods to overcome the hindrance and identify probable mistakes? } \\
\hline 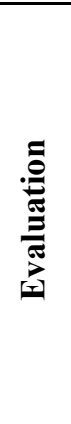 & 4. Check the Solution & $\begin{array}{l}\text { 4.1 Measure the accuracy of procedures used } \\
\text { Recheck the important information identified. } \\
\text { Consider other logical solutions. } \\
\text { 4.2 Determine the efficiency of the planning and implementation carried } \\
\text { out } \\
\text { Recheck calculation. } \\
\text { Reread the question and ask yourself whether we have answered it. } \\
\text { Determine whether the strategies and calculations are correct. }\end{array}$ \\
\hline
\end{tabular}

Teaching and learning of the strategic thinking approach through visual representation in solving mathematical word problems are based on these steps, aimed to facilitate students' understanding and ability to build a process in solving problems given in order to make sure the plan is suitable to derive the correct answer. Good problem solving uses various processes and strategies because students read and represent the problems before they plan on the solutions. (Montague, 2003; Montague, Warger, \& Morgan, 2000). The steps of the questioning process below are conducted in the strategic thinking approach through visual representation to solve the given mathematical word problem.

\section{Step 1}

Instruction: Read given problem and understand what is being asked.

Questioning: Do you understand the problem? If not, read again and underline the information. See the 
connection with the value given and extract information. What is being given? What is being sought?

Check: If the problem is already understood, Picture it.

Step 1:

Visualization: Question: What type of visual is suitable to represent?

Draw figures/models/sketches/etc. What do you understand from the visual drawn?

Checking: I have drawn the correct visual representation.

Step 2:

Arrangement: Question: Can the visual drawn represent the interconnected values in each part of the question?

Checking: If they cannot, rebuild a more suitable visual representation by drawing figures/models/sketches/etc. that represent the interconnected values in the problem given.

\section{Step 2}

Instruction: Plan how to proceed with the solution.

Questioning: Have you given any value to the connection made with the visual? What is the most suitable operation and how should you proceed with calculation?

Check: Use the visual built and ask yourself if you have made the correct measures.

\section{Step 3}

Instruction: Calculate to get the answer.

Questioning: Have you done all the calculations right and made the precise steps?

Check: All operations have been executed and the correct answer is obtained.

\section{Step 4}

Instruction: Check answer.

Questioning: Are all the answers given reasonable and accurate? Have you done any rechecking?

Check: Is everything correct? If not, solve again and ask for teachers' assistance if required.

\section{Example of students' answers in a mathematics test:}

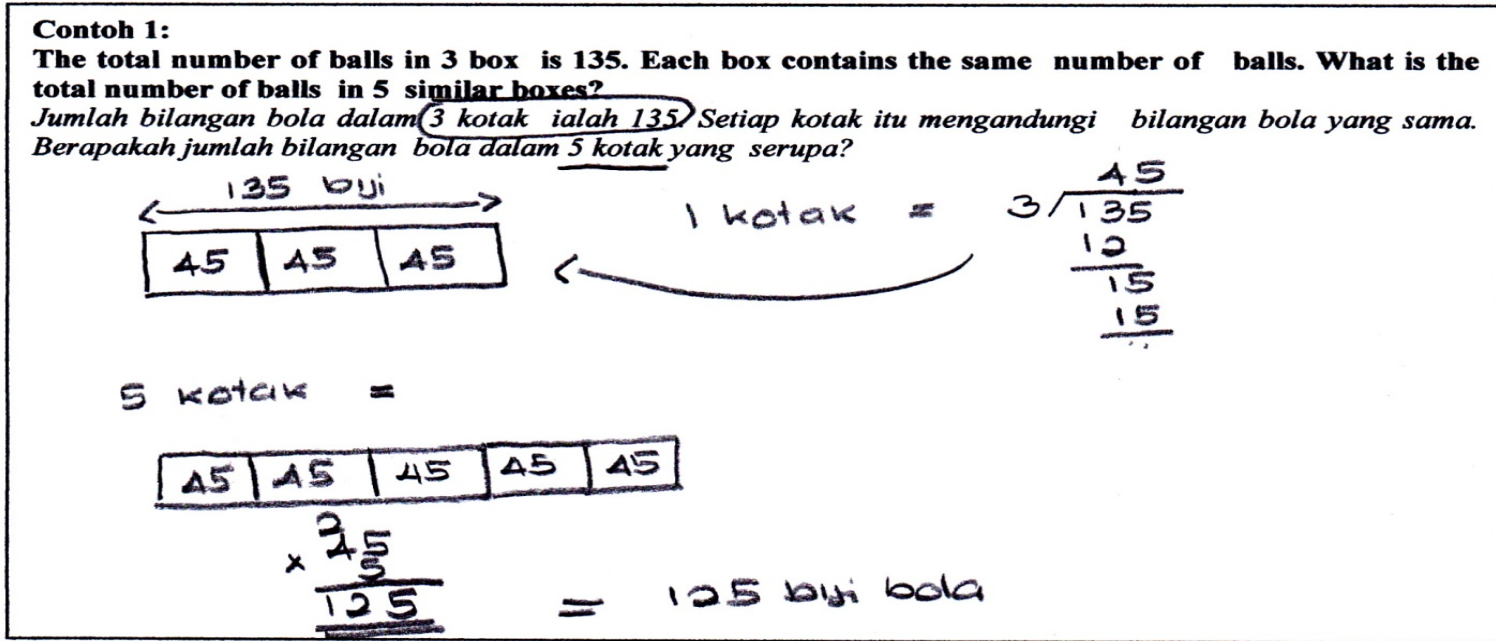




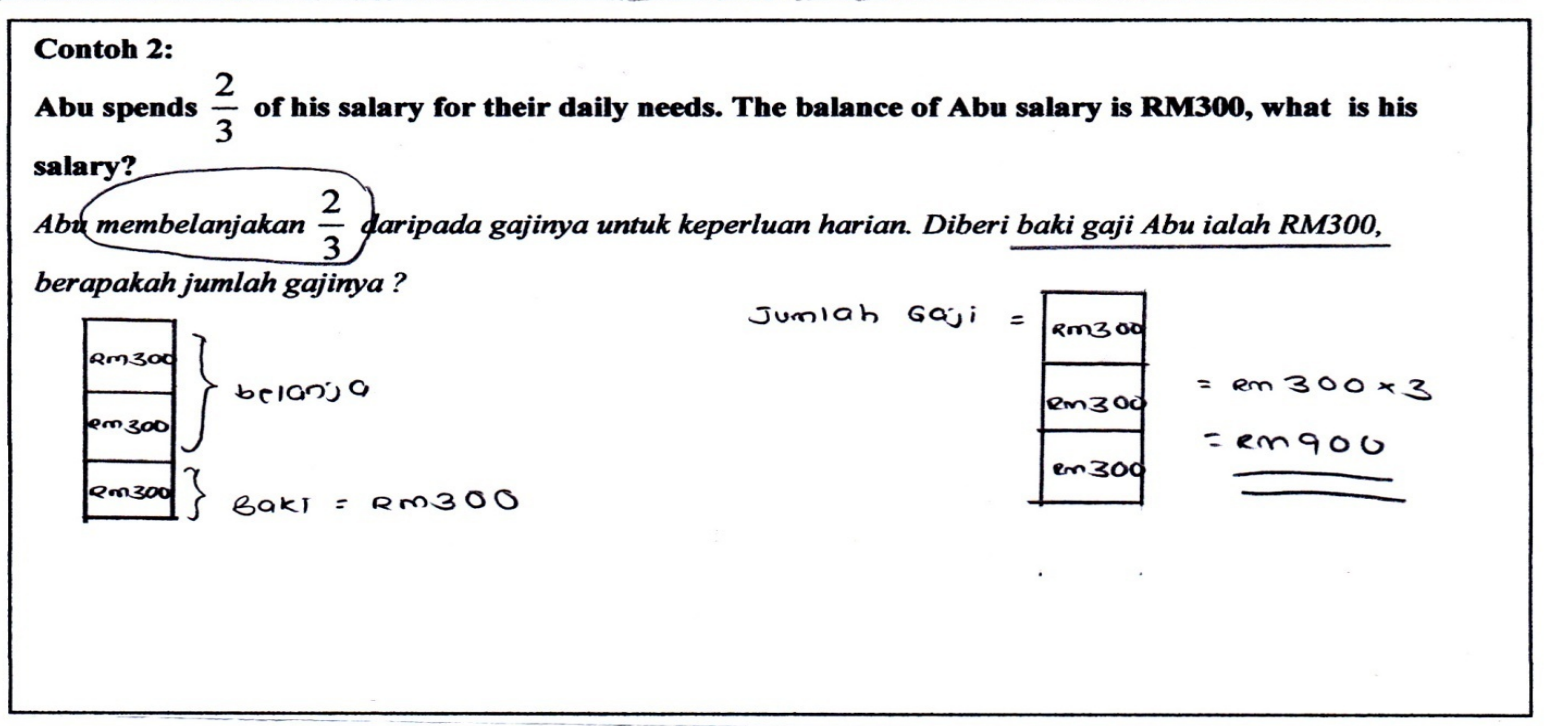

\section{Discussion and Conclusion}

Findings of the study showed that it is important to create a representation of the mathematical problem. Students are able to visualize the problems through the created representation and students are able to indicate the concepts and mathematical procedures needed to solve the mathematical problems successfully. The teaching of word problems in Malaysia often resembles the teaching of any other mathematical problems. Students are given as much information as possible and the focus of the information is on facts and procedures followed by drill and practice, as well as rote learning. Thus, there is less emphasis on the development of thinking skills and creation of a representation in problem solving. On the other hand, this study showed that when the teaching approaches encourage students to apply thinking strategies through using visual representation, students are able to gain a better conceptual understanding and eventually improve their mathematics achievement. This is because students are involved actively in their learning. As argued by Schoenfeld (1992), employing thinking skills and creating visual representations in mathematics teaching and learning are important in developing students' mathematical concepts. It is more so in solving word problems as highlighted by Polya (1957), Beyer (1988), Krulik and Rudnick (1996), Goldin (1998), and Stylianou (2000).

Visual representations of the word problems serve as a medium to assist the students in understanding the problem. Students are further found to be able to make connections with the concepts in solving the problem when they are taught to think about the problem analytically. This finding parallels the findings from Rittle-Johnson and Star (2007) in that representing the word problems visually is the mechanism that enhances students' conceptual and procedural knowledge. As argued by Pape (2004), students who were successful in solving mathematical problems tend to create visual representations of the word problem and the representations were able to facilitate the students recalling previous mathematical knowledge to solve the problems. Visual representations also help the students to integrate the recalled information with new information presented in the word problems.

The innovative and novel teaching approach employed in this study showed a positive impact on the students' understanding of mathematical concepts and ability to solve word problems successfully. Thus, mathematics teachers need to be open and proactive in adopting new approaches to mathematics teaching that have an impact on students' mathematics learning. In particular, the students' ability to solve word mathematical problems improved significantly. The teaching approach used in this study serves as a beginning and a guide for mathematics teachers to encourage creating visual representations among students when attempting to solve word problems. The ability to solve mathematical word problems is further enhanced when thinking strategies are applied in solving the problems.

\section{References}

Beyer, B. K. (1988). Developing a thinking skills program. Allyn \& Bacon. Boston

Cohen, J. (1988). Statistical Power Analysis for the Behavioral Sciences (2nd ed.). Hillsdale, NJ: Erlbaum.

Geary, D. C. (2004). Mathematics and learning disabilities. Journal of Learning Disabilities, 37, 4-15. http://dx.doi.org/10.1177/00222194040370010201 
Goldin, G. A. (1998). Representational systems, learning, and problem solving in mathematics. Journal of Mathematical Behaviour, 17(2), 137-165. http://dx.doi.org/10.1016/S0364-0213(99)80056-1

Hanich, L. B., \& Jordan, N. C. (2004). Achievement-related beliefs of third-grade children with mathematics difficulties. Journal of Educational Research, 97(5), 227-233. http://dx.doi.org/10.3200/JOER.97.5.227-234

Johnson, A. (2010). Teaching mathematics to culturally and linguistically diverse learners. Boston, MA: Pearson Education.

Kiess, H. (1996). Statistical Concepts for the Behavioural Sciences (2nd ed.). Boston: Allyn and Bacon.

Kilpatrick, J. (2001). Understanding mathematical literacy: the contribution of research. Educational Studies in Mathematics, 47, 101-116. http://dx.doi.org/10.1023/A:1017973827514

Knight, M. (2000). System and software visualization. Durham, UK: World Scientific.

Krulik, S., \& Rudnick, J. A. (1996). The new sourcebook for teaching reasoning and problem solving in junior and senior high school. Boston: Allyn \& Bacon.

Lager, C. (2006). Types of mathematics-language reading interactions that unnecessarily hinder algebra learning and assessment. Reading Psychology, 27(2-3), 165-204. Retrieved May 30, 2009, from Communication and Mass Media Complete database. http://dx.doi.org/10.1080/02702710600642475

Lesh, R., \& Harel, G. (2003). Problem solving, modeling, and local conceptual development, mathematical thinking and learning. An International Journal, 5(2-3), 157-190.

Ministry of Education, Malaysia. (2003). Syllabus Integrated Primary School Curriculum. Ampang: Dawana.

Mohd Daud Hamzah. (2002). Workshop paper on quality improvement of teaching methods for Mathematics and Islamic Studies for matriculation programme by the Ministry of Education Malaysia. Kuala Lumpur. 5-8 Ogos, 2002.

Montague, M. (2003). Solve It! A practical approach to teaching mathematical problem solving skills. Reston, VA: Exceptional Innovations.

Montague, M., Warger, C. L., \& Morgan, H. (2000). Solve It! Strategy instruction to improve mathematical problem solving. Learning Disabilities Research and Practice, 15, 110-116. http://dx.doi.org/10.1207/SLDRP1502_7

National Council for Teachers of Mathematics (NCTM). (2000). Principles and standards for school mathematics. Reston, VA: NCTM.

Northwest regional Educational Laboratory (NWREL). (2000). Mathematics problem solving scoring guide. Mathematics and Science Education Centre. Retrieved June 18, 2010, from http://www.nwrel.org/msec/mpm/scoring.html

Pape, S. J. (2004). Middle school children's problem-solving behavior: A cognitive analysis from a reading comprehension perspective. Journal for Research in Mathematics Education, 35, 187-219. http://dx.doi.org/10.2307/30034912

Parkinson, A., \& Redmond, J. A. (2002). The impact of cognitive styles and educational computer environments on learning performance. Dublin, Ireland: Trinity College, Dept of Computer Science.

Polya, G. (1957). How to solve it: a new aspect of mathematical method (2nd ed.). New Jersey: Princeton University Press.

Powell, S. R., Fuchs, L. S., Fuchs, D., Cirino, P. T., \& Fletcher, J. M. (2009). Do word-problem features differentially affect problem difficulty as a function of students' mathematics difficulty with and without reading difficulty? Journal of Learning Disabilities, 42, 99-110. http://dx.doi.org/10.1177/0022219408326211

Presmeg, N. C. (1986). Visualisation in high school mathematics. For the Learning of Mathematics, 6(3), 42-46.

Rittle-Johnson, B., \& Star, J. R. (2007). Does comparing solution methods facilitateconceptual and procedural knowledge? An experimental study on learning to solve equations. Journal of Educational Psychology, 99(3), 561-574. http://dx.doi.org/10.1037/0022-0663.99.3.561

Schoenfeld, A. (1992). Cognitive Science \& Mathematics Education Overview. Hillsdale: NJ. Erlbain.

Scommer-Aikins, M., Duell, O. K., \& Hutter, R. (2005). Epitemological beliefs, Mathematical problem-solving beliefs, and academic performance of middle school students. The Elementary School Journal, 105(3), 
290-304.

Stylianou, D. (2001). On the reluctance to visualize in mathematics: Is the picture changing? In M. van den Heuvel-Panhuizen (Ed.), Proceedings of the 25th Conference of the International Group for the Psychology of Mathematics Education (Vol. 4, pp. 225-232). Utrecht, The Netherlands: Freudenthal Institute.

Stylianou, D. A. (2002). On the interaction of visualization and analysis: the negotiation of a visual representation in expert problem solving. Journal of Mathematical Behavior, 21, 303-317. http://dx.doi.org/10.1016/S0732-3123(02)00131-1 